\title{
ARTE COMO CONHECIMENTO DO MUNDO NA METODOLOGIA CRIATIVA E PEDAGÓgICA DO PROJETO 'DE FORA ADENTRO - CARTOGRAFIA DOS SENTIDOS”
}

\author{
Maurício Camargo Panella ${ }^{1}$ \\ Miguel Gally ${ }^{2}$ \\ Mariana Fidelis ${ }^{3}$
}

\section{Resumo}

Diante dos diversos e complexos problemas sociais e ambientais que a humanidade desenvolve e tem que enfrentar nos dias atuais, principalmente nas grandes metrópoles mundiais, a arte como meio de conhecer, ler, perceber e imaginar o mundo se mostra como uma linguagem propiciadora de inovadoras vias de comunicação e interação entre o ser humano, o meio social e o meio natural. Neste artigo mostramos algumas das metodologias transpedagógicas de cartografia artística que o Projeto De Fora Adentro- Cartografia dos Sentidos vem desenvolvendo desde 2010 em algumas capitais do Brasil.

Palavras chaves: Arte, cartografia, popularização da ciência, transpedagogia.

\begin{abstract}
Facing the variety of complex social and environmental problems that humankind has to deal with nowadays, mainly in the world's metropolises, art has a key role as a mean of knowing, reading, perceiving and imagining the world. Art is a language that propitiates new ways of communication and interaction between human beings and social and natural environments. On this article is presented some artistic cartography transpedagogic methodologies used in the project From out to inside - sensitive cartography, that has been taking place in some capitals of Brazil since 2010.
\end{abstract}

Key words: Art, cartography, science accessibility, transpedagogy

\footnotetext{
${ }^{1}$ Antropólogo, sociólogo e artista multimídia. Doutorando pela Facultad de Bellas Artes de Granada- Espanha. Fundador do Instituto Casadágua- Arte, Educação e Sustentabilidade. Pesquisador do Núcleo de Estética e Semiótica- Programa de Pós Graduação de Arquitetura e Urbanismo da UNB.

${ }^{2}$ Professor da Faculdade de Arquitetura e Urbanismo da Universidade de Brasília.

${ }^{3}$ Professora colaboradora Júnior do Programa de Pós-Graduação em Filosofia da Universidade de Brasília (PPGFIL/UnB) e pesquisadora do Instituto Casa D'Agua (Natal-RN). Bacharelado e Licenciatura em Filosofia (UFPE), Mestrado em Filosofia (UFMG) com ênfase em História da Filosofia Contemporânea.
} 
Passamos por profundas transformações urbanas e sociais, e a população pouco conhece o espaço em que vive: formações geológicas, lagoas, rios, ruas e avenidas, praias, monumentos, praças, prédios históricos, etc. Desde a década de 1980, sobretudo, com o início dos debates em escala mundial sobre sustentabilidade, sobre o uso regulado e responsável dos recursos naturais tanto para a manutenção quanto para a melhoria da qualidade de vida, vem sendo diagnosticado o esgotamento dos modelos de cidade e práticas de urbanização voltadas para o crescimento desorganizado; um crescimento que tem se dado não só a um alto custo material e natural, mas também social, com aumento crescente dos conflitos, da violência e do distanciamento entre os que vivem na cidade, segmentações em grupos de classe, além de um desconhecimento da cidade em que se vive, do espaço social, arquitetônico e urbano em sua complexa engrenagem. Escapa ao cidadão, pela rotina cotidiana e a falta de uma visão mais ampla, o complexo de relações sociais e a organização sócio espacial que encadeia bairros, zonas comerciais, centros político-financeiros, portos e praias, zonas norte e sul. Poderíamos aqui parodiar o ex-diretor do INPE (Instituto Nacional de Pesquisas Espaciais) Gilberto Câmara, dizendo que o cidadão não conhece a cidade onde mora, pensando na sua afirmação de que "o Brasil não conhece o Brasil" e isso não somente de uma perspectiva cartográfica. Porque escapa também ao cidadão toda uma temática da consciência e ética (respeito, pertencimento, identidade, segregação etc.), da apropriação e do reconhecimento das várias dimensões que compõem o espaço da cidade (ecológica, política, geográfica, antropológica, urbanística, jurídica, poética, etc.).

Neste contexto, o projeto "De Fora adentro: Cartografia dos Sentidos", criado e desenvolvido pelo antropólogo e artista Maurício Camargo Panella, desde de seu lançamento na $62^{\circ}$ SBPC- na cidade do Natal no Rio Grande do Norte em 2010, através da construção coletiva de instalações compostas por mapas gigantes de cidades (cartografia macroscópica) e de mostras artístico-lúdicas e interativas (cartografia microscópica), proporciona aos grupos sociais envolvidos nas atividades de criação da obra, a possibilidade da "criação de mundos", ou seja, da apropriação poética e estética da cidade em que vive, a partir de reflexões que auxiliem e abram o sentido de percepção local ligada a um todo. A "criação de mundos" é uma das tarefas fundamentais da cartografia, uma ciência tão ou mais antiga do que a escrita, embora o batismo com esse nome seja bem recente (século XIX).

\footnotetext{
${ }^{4}$ Texto disponível em: http://www.inpe.br/noticias/noticia.php?Cod_Noticia=923.
} 


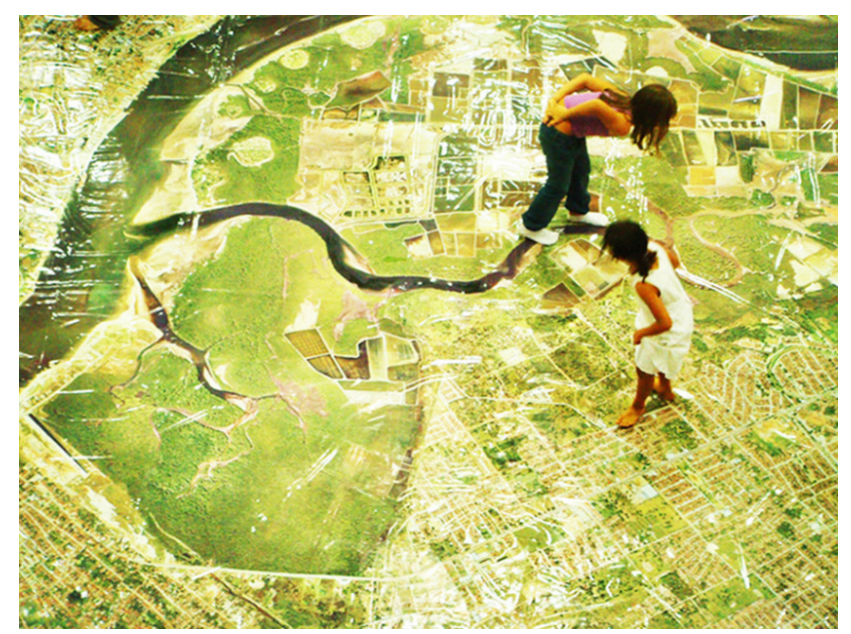

Figura 1 - Imagens do Projeto De Fora adentro- Natal, lançado em 2010 na $62^{\circ}$ SBPC

Data - 2010

A cartografia, desde uma perspectiva etimológica, é a visualização gráfica ou escrita dos mapas e é definida pela Associação Internacional de Cartografia (ICA) como "conjunto dos estudos e operações científicas, técnicas e artísticas que intervêm na elaboração dos mapas a partir dos resultados das observações diretas ou da exploração da documentação, bem como da sua utilização" ". A cartografia, assim, dentre outras atividades, é uma ciência das referências de localização e fronteiras para que se possa, por exemplo, percorrer distâncias por caminhos seguros e não às cegas. A elaboração de mapas está diretamente ligada às viagens, expedições e, nesse sentido, a cartografia guarda dentro dela a curiosidade própria do conhecimento científico, aquele desejo natural que a humanidade tem pelo conhecimento (Metafísica de Aristóteles, 2012, p.3), ou seja, por sua produção. E desse modo, a "criação de mundos" é entendida não apenas como a criação de mapas e reconhecimento de localidades, mas a criação de relações com a realidade baseada em conhecimentos, porque desejar conhecer é desejar um tipo de relação esclarecedora com a realidade.

\footnotetext{
${ }^{5}$ Texto disponível em: http://icaci.org/.
} 


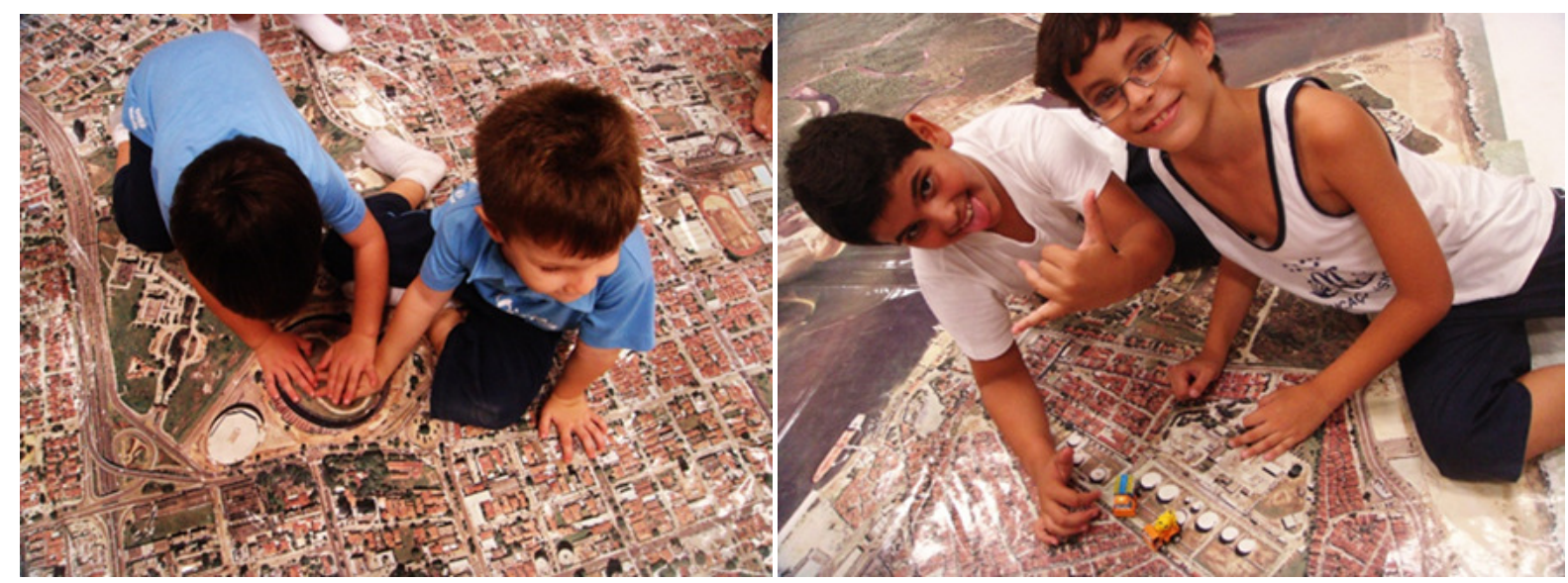

Figura 2 e 3 - Imagens do Projeto De Fora adentro- Natal, lançado em 2010 na $62^{\circ}$ SBPC

Data -2010

É partir desse contexto amplo que o projeto "De fora adentro - Cartografia dos sentidos" pretende se colocar, na medida em que encara o desconhecimento dos espaços cotidianos das cidades nas quais habitamos. E, ao ampliar o conhecimento e as relações que mantemos com nossas cidades, o projeto pretende também ampliar o aspecto essencialmente visual da cartografia, lembrando a possibilidade da criação de "mapas de ouvir", "mapas lúdicos", "mapas tácteis", "mapas oníricos”, "mapas de memórias”, "mapas de sentidos”.

Essa composição de cartografias sensíveis se utiliza de um diálogo da "perspectiva macroscópica" oferecida pelos mais recentes recursos de cartografia (mapas gigantes impressos a partir de fotos de satélite -) com a perspectiva microscópica (criações artísticas e oficinas pedagógicas oferecidas e expostas sobre o mapa gigante). Com isso objetiva-se propiciar tanto uma maior compreensão da geografia da cidade como um todo, sua geopolítica, sua organização intrincada e extensa, como uma compreensão sobre os territórios subjetivos dos sujeitos envolvidos nas atividades desenvolvidas em escolas públicas e outros espaços das cidades.

\section{TRANSPEDAGOGIA: ARTE E CARTOGRAFIA}

"De fora adentro - Cartografia dos sentidos" é um projeto artístico pedagógico que aposta na criação artística e na elaboração de metodologias lúdicas e interativas o qual reúne artistas e pesquisadores multidisciplinares que se debruçam sobre as cidades para captar, registrar, sentir e perceber as nuances que o dia a dia não permite, não desvenda, não abre, a 
olhos nus e ouvidos mocos. É um projeto de divulgação e democratização do conhecimento científico, na medida em que torna sensível, apreensível e palpável o mundo da topografia, revela as fragilidades urbanísticas, investiga as intervenções sociais no espaço e no tempo.

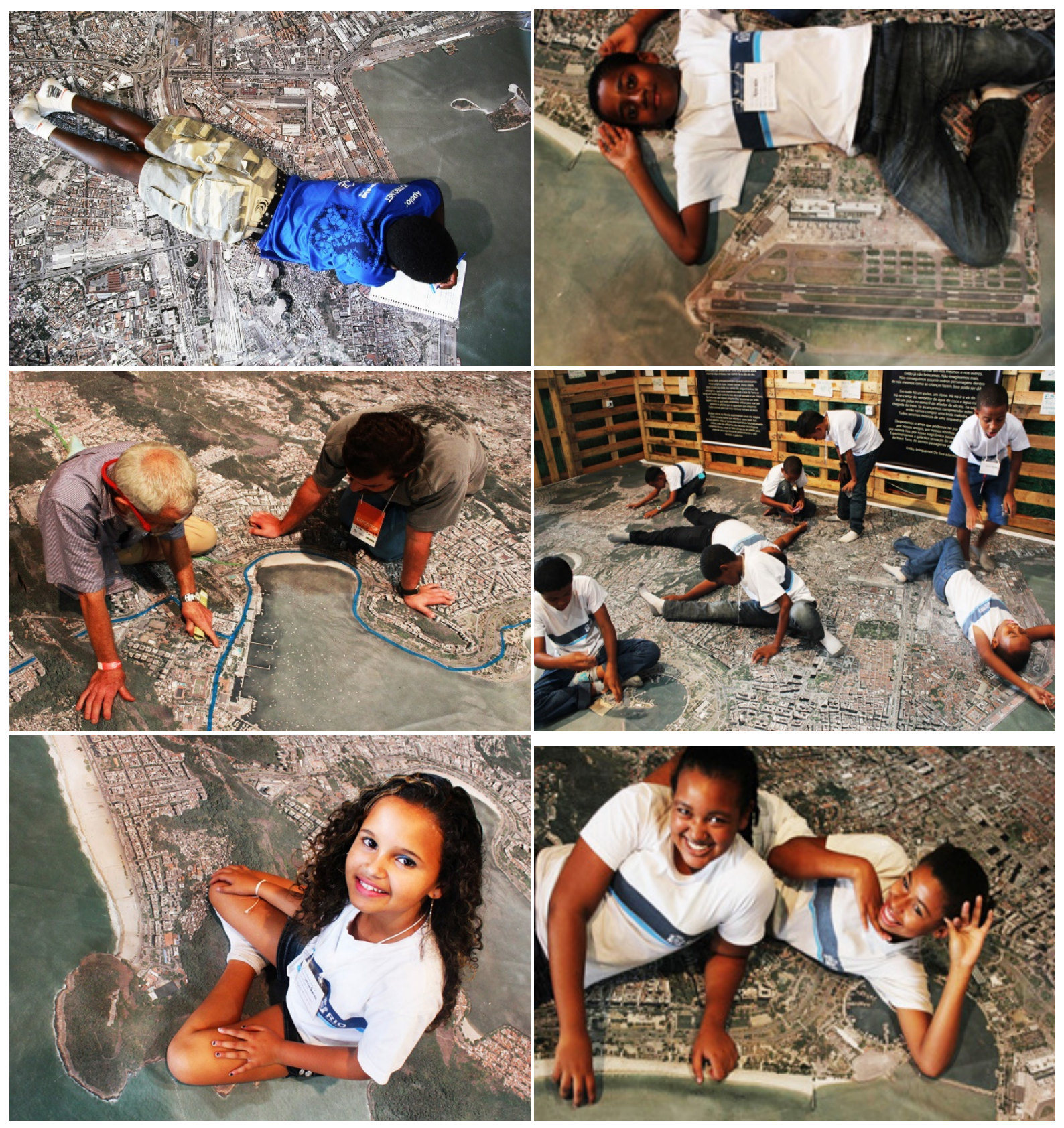




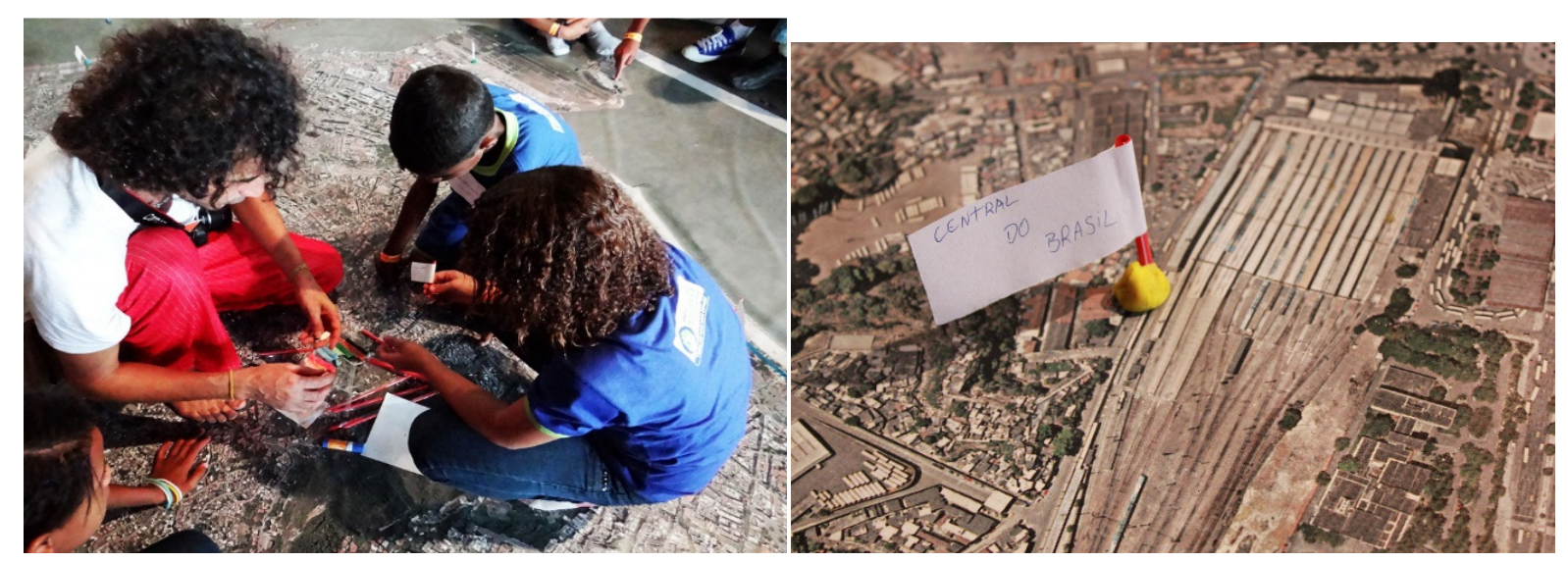

Figuras 5,6,7,8,9,10 e 11 - Imagens do Projeto De Fora Adentro

Lançadas no Rio de Janeiro lançado na Rio +20

Data -2012

É um projeto transpedagógico, como diz Pablo Helguera (2011), que convida o público a compor também dados novos para a exposição, a debruçar-se sobre a obra e encontrar-se nela e buscar encontrar também novas soluções para o convívio humano dentro das grandes cidades. A transpedagogia mediada pela arte liga os saberes para a transversalidade do conhecimento que compreende o todo que abarca a experiência humana.

Sincronicamente às atividades desenvolvidas em Natal, na $8^{\mathrm{a}}$ Bienal do Mercosul, que teve como tema "Ensaios de Geopoética" o projeto de curadoria pedagógica orientado por Pablo Helguera estimulou em seus participantes reflexões sobre novas atitudes em relação ao mundo objetivando tornar visível o processo de aprendizagem como ato criativo ao estabelecer o paralelo entre o fazer artístico e a geração de conhecimento. Transpedagogia: arte contemporânea e os veículos educativos; Arte como prática social; Arte como conhecimento do mundo; Educação para uma arte socialmente engajada; Pedagogia no campo expandido foram os eixos que demarcaram o Projeto Pedagógico da Bienal de 2011 em Porto Alegre.

\section{EDUCAÇÃO, ARTE, CARTOGRAFIA E ECOLOGIA}

Como projeto de extensão junto ao Núcleo de Arte e Cultura da Universidade Federal do Rio Grande do Norte, desenvolveu-se, além dos produtos criativos, uma metodologia aliada ao curso de Ecologia, que utilizou o cenário fotográfico (Mapa Gigante) para realizar oficinas de sensibilização em escolas públicas da capital a respeito da 
configuração urbanística que aglutina parques naturais, lagoas, dunas e rios. Com o bolsista e ecólogo José Guedes mapeou-se as áreas verdes da cidade de Natal. Na semana do Meio Ambiente, organizada pelo Instituto Federal do Rio Grande do Norte, José Guedes coordenou uma oficina onde alunos da escola puderam compreender e analisar o mapa de sua cidade com esta lente de aumento.
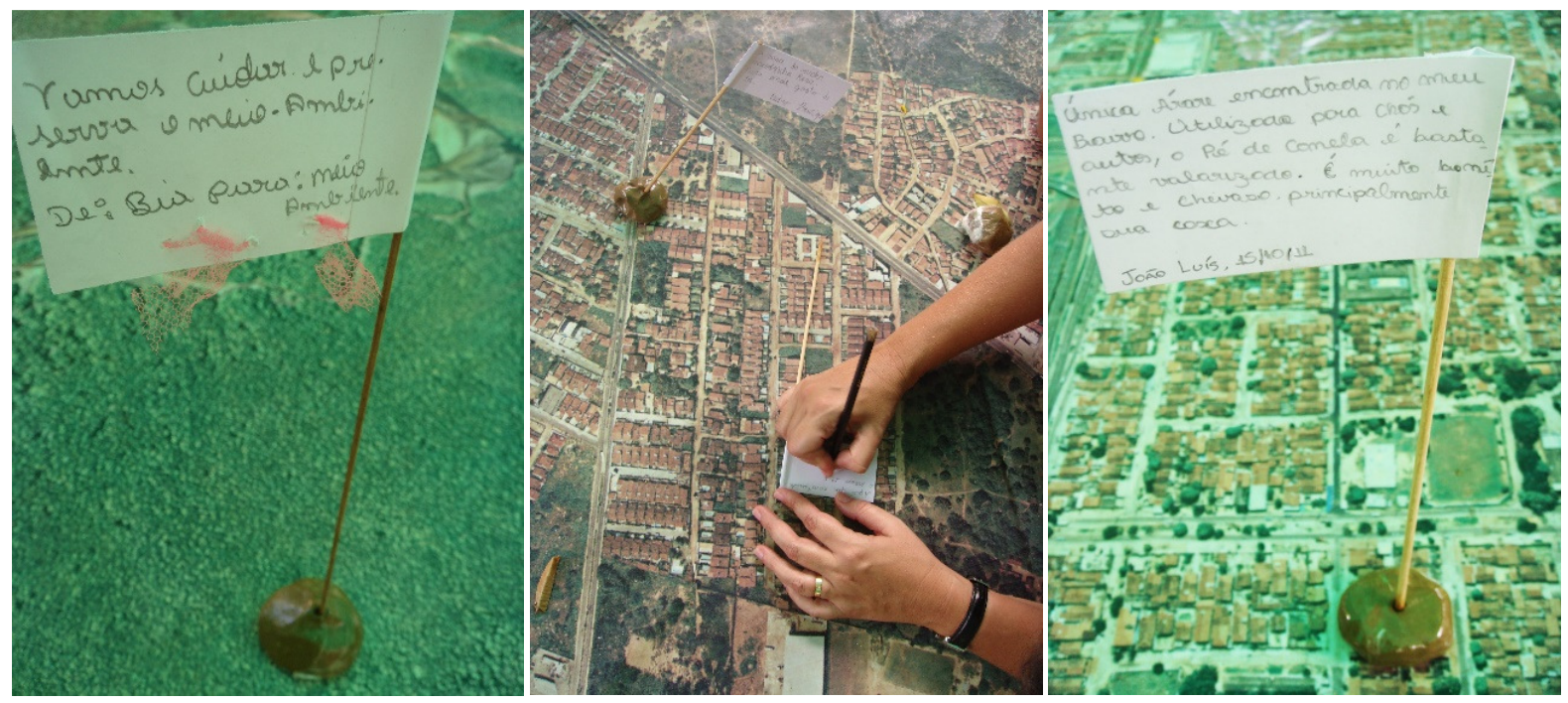

Figuras 12,13 e 14 - Imagens De Fora adentro - Natal

Data - 2011

Esta concepção de que arte pode servir a essa tarefa de acesso aos conhecimentos científicos não é recente e remonta pelo menos a Alexander Baumgarten (século XVIII) que batizou o termo Estética (AMOROSO, 1996), entendendo-a como um tipo de conhecimento (BAUMGARTEN, 1993; §§1-13): "perfeição do conhecimento sensível” na medida em que conseguia expor em um domínio acessível a todos, o domínio das sensações, um conhecimento lógico-discursivo restrito, que hoje reconheceríamos, grosso modo, como o conhecimento técnico-científico. A estética, entendida como parâmetro para definição de arte, guarda esse privilégio quando o tema é democratização do conhecimento. Mas isso quer dizer também que arte pode ser entendida como um conhecimento, como uma maneira de se relacionar com a realidade capaz de provocar reflexões e, em alguns casos, esclarecimentos, de uma maneira mais sensível ou tocando em sentimentos. É o caso quando ao caminhar sobre o mapa gigante nos relacionamos com nossa cidade como se fossemos um satélite, como se tivéssemos um olho de satélite, ou seja, como se pudéssemos entender essa tecnologia nos colocando em seu lugar, e nos relacionando com a cidade do ponto de vista do satélite: vendo-a como um todo. 
Diante dessa apreensão, ao mesmo tempo fragmentada e holística, da cidade, objetiva-se promover a formação de uma consciência da cidade enquanto totalidade, uma totalidade conectada, interligada, interdependente. A partir deste olhar abrangente sobre a cidade, podemos nos apropriar dela, identificando, por exemplo, a geografia que a compõe, quais seus caminhos, seus cumes, seus vales. Ao caminhar por "De fora adentro" se quer encontrar a própria casa, a casa das avós, a escola onde se estuda, a rota da casa que leva a mundos conhecidos.
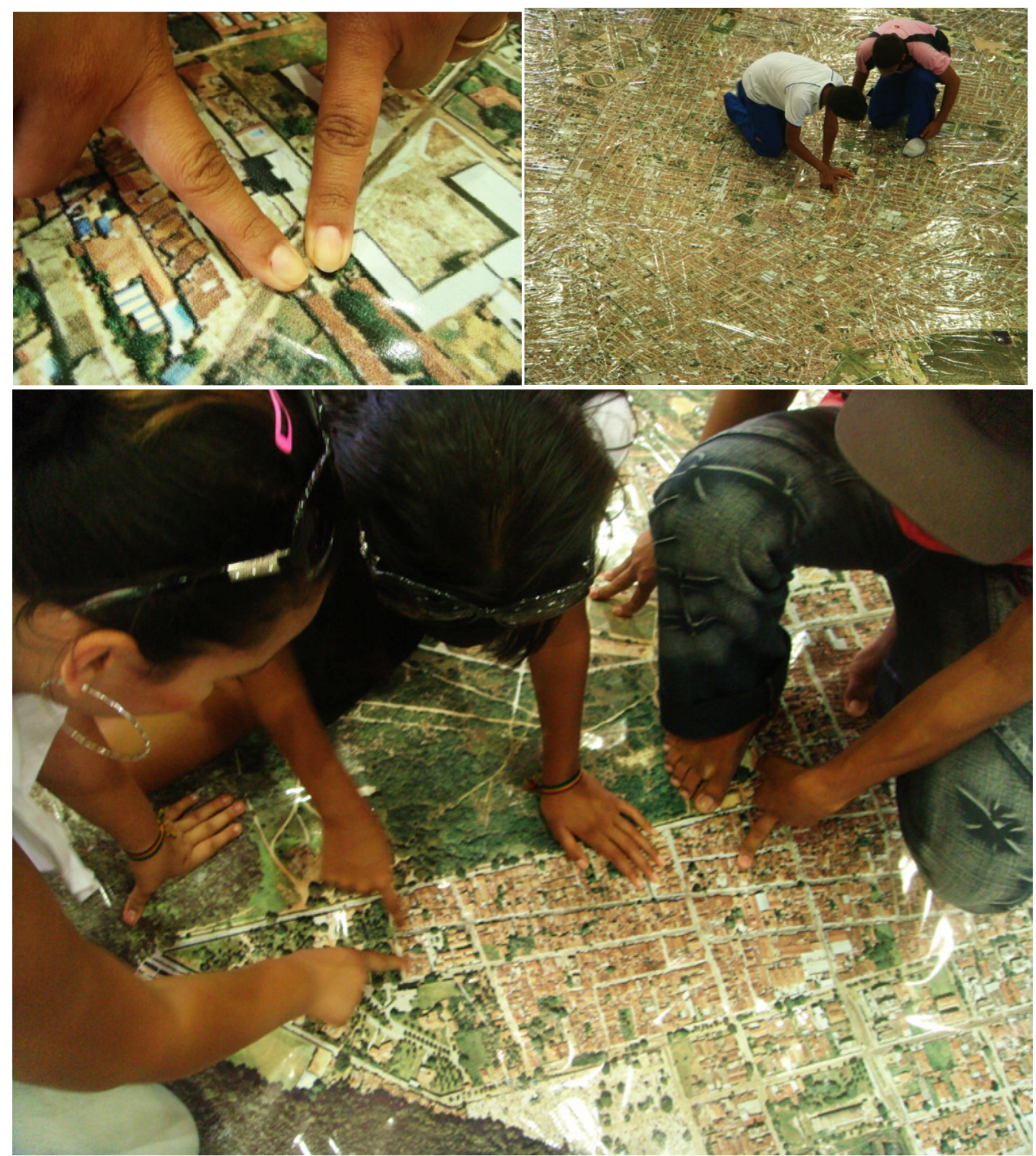

Figuras 15,16 e 17 - Imagens De Fora adentro - Natal

Data - 2011 
Essa é a experiência de se identificar no meio do todo, no meio da grande cidade que parece na maior parte das vezes maior do que nós. Sobre um mapa gigante, todas as referências básicas de localização regeneram-se: o indivíduo redimensiona sua relação com a cidade, pois a noção daquela distância percorrida cotidianamente de carro ou ônibus, agora é modificada, transposta na escala de um passo. Essa mudança de referência causa um estranhamento do que antes era óbvio e natural e ao mesmo tempo um reconhecimento crítico e afetuoso sobre nossos costumes, formas de viver, formas de pensar nossas atitudes e comportamentos com o que é individual, social, biológico e cósmico. Assim, o projeto se desenvolve no sentido de provocar a partir do contato sensível com a tecnologia uma experiência de re-conhecimento e pertencimento entre o indivíduo e sua localidade, uma experiência de interdependência que impõe ao mesmo tempo um senso maior de responsabilidade e cuidado no que diz respeito ao espaço urbano onde se vive. E, mais que isso, em relação ao meio ambiente que compõe a cidade, pois, na medida em que podemos enxergar o extremo norte e o extremo sul, ver os vários braços de rios, lagos, matas que a compõe, podemos enxergar as fronteiras entre a natureza e a ocupação humana, podemos enxergar de modo, literalmente, "concreto" a atuação humana destrutiva com a diversidade da vida biológica natural.

\section{CONSIDERAÇÕES FINAIS}

Portanto, o projeto proporciona, tanto para os envolvidos nas atividades pedagógicas, quanto para os espectadores da exposição, uma noção quanto às relações geográficas, sociais, econômicas e ambientais que se estabelecem dentro do espaço urbano, contribuindo enfaticamente para a conscientização acerca da dimensão político-jurídica do conceito de espaço. A experiência de imersão na cidade vista como um todo contribui para a formação crítica a respeito do ordenamento do espaço público e seu caráter político; contribuindo, de uma maneira geral, por exemplo, para o debate acerca dos direitos urbanos recentemente instaurados no Brasil. A consciência de interdependência alcança os sentimentos de pertencimento e, ao mesmo tempo, responsabilidade, ao perceber que a cidade é uma parte do que somos, e de que somos uma parte da cidade. Assim, aliado ao conhecimento científico, se quer estimular a crítica e o exercício da cidadania através da arte e das tecnologias. "A cidade", avalia a arquiteta e urbanista Paola Berenstein Jacques (2007), "ganha corpo quando 
é praticada. Só assim pode surgir uma outra forma de apreensão da cidade, e, consequentemente, de reflexão e intervenção na cidade".

\section{REFERÊNCIAS BIBLIOGRÁFICAS}

AMOROSO, L. (Org.) Il Battesimo dell’estetica, Pisa: ETS, 1996, 2.ed.

ARISTÓTELES. Metafísica. Trad. Valentin Garcia Yebra, Madrid: Gredos, p. 3, 2012.

BAUMGARTEN, Alexander G. Estética: A lógica da arte e do poema (Incluindo Meditações filosóficas sobre alguns tópicos referentes à essência do poema; extratos de Estética e Metafísica). Trad. De M.S. Medeiros, Petrópolis: Vozes, 1993.

BOURRIAUD, Nicolas. Radicante. Buenos Aires: Adriana Hidalga Editora, 2009

HELGUERA, Pablo. “Transpedagogia”. In: Pedagogia no campo expandido / Organização:

Pablo Helguera e Mônica Ho $\square$; tradução de Camila Pasquetti, Camila Schenkel, Carina Alvarez, Gabriela Petit, Francesco Settineri, Martin Heuser e Nick Rands. Porto Alegre: Fundação Bienal de Artes Visuais do Mercosul, 2011

JACQUES, Paola Berensteisn. "Corpografias urbanas - o corpo enquanto resistência". In:

Cadernos PPGAU - FAUFBA. Resistências em espaços opacos. Ano 5, número especial, Salvador: 2007.

ROLNIK, Suely. Cartografia sentimental: transformações contemporâneas do desejo. São Paulo: Estação Liberdade, 1989.

SCHAFER, Raymond Murray. A Afinação do Mundo: uma exploração pioneira pela história passada e pelo atual estado do mais negligenciado aspecto do nosso ambiente: a paisagem sonora. Tradução Marisa Trench Fonterrada, São Paulo: Editora UNESP, 1997.

O ouvido pensante. Tradução de Marisa T. O. Fonterrada, Magda R. G. Silva e Maria Lúcia Pascoal, São Paulo: Editora UNESP, 1991 